\title{
Pulmonary embolism and screening for concomitant proximal deep vein thrombosis in noncritically ill hospitalized patients with coronavirus disease 2019
}

\author{
Chiara Lazzeri $^{1}$ [ $\cdot$ Manuela Bonizzoli $^{1} \cdot$ Andrea Franci $^{1} \cdot$ Filippo Socci $^{1} \cdot$ Adriano Peris $^{1}$
}

Received: 14 July 2020 / Accepted: 22 July 2020 / Published online: 29 July 2020

(c) Società Italiana di Medicina Interna (SIMI) 2020

\begin{abstract}
Alterations in the coagulation system related to COVID infection still represents a challenge for clinicians in every day practice despite the growing number of investigations on this topic, and some issues (i.e., timing and doses of anticoagulants, risk stratification of the hemorrhagic/thrombotic risk in each patient) remain to date to be completely understood [4-6].
\end{abstract}

Coagulation disorders are not peculiar to COVID disease since thrombotic complications and hematologic manifestations (in primis thrombocytopenia) were reported also in SARS-CoV-1 and MERS-CoV disease [7], though the latter viral diseases have been less extensively investigated. In COVID infection, alterations in the coagulation system are detectable in all patients, independently of disease severity which itself does influence the degree and extension of coagulation disorders, particularly thrombotic events. This is why every physician in charge of a COVID patient has to assess, on admission and serially on hospital course, the functional state/alterations of the coagulation system and eventually to rule out thrombotic events by screening ultrasound. Pulmonary embolism has been described as a frequent thrombotic event, often in the absence of detectable deep venous thrombosis (DVT) [1], suggesting pulmonary thrombosis, secondary to vascular damage, rather than embolism [8]. This arises questions, so far not answered, on the most efficacious antithrombotic treatment in these patients and, more importantly, on the role of pulmonary thrombosis/embolism in causing acute respiratory failure or just contributing to it.

COVID infection attacks the coagulation system mainly through an immuno-triggered thrombo-inflammation supported by both an endotheliopathy and a hypercoagulability

Chiara Lazzeri

lazzeric@libero.it

1 Intensive Care Unit and Regional ECMO Referral Centre, Azienda Ospedaliero-Universitaria Careggi, Largo Brambilla 3, 50134 Florence, Italy state. The endothelium seems to play a pivotal role in inducing the procoagulant state since COVID-19-related proinflammatory cytokines induce an endothelial injury resulting in the release of ultralarge von Willebrand factor multimers (ULVWF) involved in primary hemostasis and the overexpression of tissue factor $[7,9,10]$. No patient is spared. The phenomenon may be aggravated by other clinical factors including hypoxemia (secondary to ARDS), hyperthermia (with activation of platelets and coagulation), and/or hypovolemia (mainly secondary to diarrhea).

The more severe the COVID disease the more prominent coagulation disorders. Hypoxemia (secondary to ARDS) may also shift the basal antithrombotic and antiinflammatory phenotype of the endothelium towards a procoagulant and proinflammatory phenotype. It also induces vasoconstriction and reduced blood flow aggravates itself an endothelial dysfunction.

Several lines of evidence indicate D-dimer as a marker of a hypercoagulable state in patients with COVID infection, though a cut-off has not be established yet. The complex relationship between degree of systemic inflammatory activation, consequent hypercoagulable state and prognosis may be highlighted by the association between elevated D-dimer and severity of COVID-19 [11-14]. Moreover D-dimer on admission greater than $2.0 \mu \mathrm{g} / \mathrm{mL}$ (fourfold increase) could effectively predict in-hospital mortality in patients with COVID-19 [15] and increased D-dimer levels have gained particular attention as a predictor of the development of acute respiratory distress syndrome (ARDS), the need for admission to an intensive care unit (ICU) or death.

The relationship between coagulopathy, as an effect of systemic inflammatory activation, and outcome is not surprising since it has been reported also in other disease states such as sepsis. The peculiarity of COVID infection seems to be that as disease severity increases, the incidence of thrombotic complications, which may involve both the venous and the arterial systems, increases. A recent analysis 
from a French group showed that the rate of thromboembolic complications in 150 COVID19 patients with ARDS was much higher (11.7\%) than what observed in a historical control group of non-COVID-19 ARDS patients (2.1\%) despite anticoagulation [16]. Obviously, estimation of incidence is deeply affected by deep venous thrombosis screening protocol adopted in each hospital (clinical and/or routine ultrasound). Indeed, while in a Dutch study symptomatic DVT showed a cumulative rate of $27 \%$ in 184 critically ill patients [17], a higher incidence (25\%) was reported in a Chinese ICU with a routine VTE screening [18].

To date, all available evidence is consistent with an hypercoagulable state induced by COVID disease which parallels systemic inflammatory storm and translates into "damage" (that is thrombotic events) more frequently in severe states. This underscores the clinical need for an appropriate therapeutic regimen. In the lack of prospective trials, the choice between thromboprophylaxis and "aggressive thromboprophylaxis" is still to be considered on individual basis. Current recommendations of the Italian Society on Thrombosis and Haemostasis state that all patients (including noncritically ill) who require hospital admission for COVID19 infection should receive prophylactic dose LMWH, unless contra-indications (active bleeding and low platelet count) [19]. Data on the effect of thromboprophylaxis are still scarce and trials are still ongoing. In a retrospective analysis of 499 severe COVID patients [20], low molecular weight heparin (LMWH) or unfractionated heparin (UFH) at prophylactic doses were associated with a reduced 28-day mortality in selected severe COVID-19 patients, that is those with sepsis-induced coagulopathy (SIC) score $\geq 4$ or D-dimer levels $>$ sixfold the upper limit of normal.

As he tries to orientate himself in the growing amount of published papers, the physician of all specialties should bear in mind just a few messages for the management of a COVID patient (independently of disease severity) [21,22]. Firstly, the assessment and monitoring of the coagulation state by few biochemical parameters, in primis D-dimer and platelet count. Their clinical significance primarily relies on their dynamic variations, more than their absolute values. Secondly performing a DVT screening on admission, and, subsequently, on clinical suspicion. Thirdly, to assess in the single patient, the hemorrhagic/thrombotic profile, taking into account disease severity, preexisting conditions (i.e., chronic atrial fibrillation) and acute organ dysfunction (i.e., acute renal failure). This would lead to a tailored anticoagulant therapy.

More severe patients, as those on extracorporeal membrane oxygenation support, have not been so extensively investigated to date. In these patients characterized by a high hypercoagulable state due to disease severity (and despite therapy), screening should be more accurate as well as monitoring coagulation to prevent bleeding events.
Funding No funding.

\section{Compliance with ethical standards}

Conflict of interest The author(s) declare that they have no conflict of interest.

Statement of human and animal rights This article does not contain any studies with human participants or animals performed by any of the authors.

Informed consent None.

\section{References}

1. Dubois-Silva A, Barbagelata-López C, Mena A, Piñeiro-Parga P, Llinares-García D, Freire-Castro S (2020) Pulmonary embolism and screening for concomitant proximal deep vein thrombosis in noncritically ill hospitalized patients with coronavirus disease 2019. Intern Emerg Med 26:1-6

2. Landi A, De Servi S (2020) The burden of thrombotic complications in critically ill patients with COVID-19: charting the uncharted. Intern Emerg Med 5:1-3

3. Bertolino L, Vitrone M, Durante-Mangoni E (2020) Does this patient have COVID-19? A practical guide for the internist. Intern Emerg Med 23:1-10

4. Poli D, Tosetto A, Palareti G, Barcellona D, Ciampa A, Grandone E, Manotti C, Moia M, Squizzato A, Toschi V, Testa S, On the behalf of Italian Federation of Anticoagulation Clinics (FCSA) (2020) Managing anticoagulation in the COVID-19 era between lockdown and reopening phases. Intern Emerg Med 8:1-4

5. Allione A, Giamello JD, Paglietta G, Bernardi S, Cavalot G (2020) Switch from oral anticoagulants to parenteral heparin in SARSCoV-2 hospitalized patients: comment. Intern Emerg Med 21:1-2

6. Testa S, Paoletti O, Giorgi-Pierfranceschi M, Pan A (2020) Switch from oral anticoagulants to parenteral heparin in SARS-CoV-2 hospitalized patients. Intern Emerg Med 15:1-3

7. Joly BS, Siguret V, Veyradier A (2020) Understanding pathophysiology of hemostasis disorders in critically ill patients with COVID-19. Intensive Care Med 2020:1-4

8. Cattaneo M, Bertinato EM, Birocchi S, Brizio C, Malavolta D, Manzoni M et al (2020) Pulmonary embolism or pulmonary thrombosis in COVID-19? Is the recommendation to use highdose heparin for thromboprophylaxis justified? Thromb Haemost. https ://doi.org/10.1055/s-0040-1712097

9. Varga Z, Flammer AJ, Steiger P et al (2020) Endothelial cell infection and endotheliitis in COVID-19. Lancet 395(10234): 1417-1418

10. Jung F, Krüger-Genge A, Franke RP, Hufert F, Küpper JH (2020) COVID-19 and the endothelium. Clin Hemorheol Microcirc. https ://doi.org/10.3233/CH-209007

11. Lippi G, Favaloro EJ (2020) D-dimer is associated with severity of coronavirus disease 2019: a pooled analysis. Thromb Haemost 120:876-878

12. Iba T, Levy JH, Connors JM, Warkentin TE, Tachil J, Levi M (2020) The unique characteristics of COVID-19 coagulopathy. Crit Care 24:360

13. Wu Z, McGoogan JM (2020) Characteristics of and important lessons from the coronavirus disease 2019 (COVID-19) outbreak in China: summary of a report of 72314 cases from the Chinese Center for Disease Control and Prevention. JAMA. https://doi. org/10.1001/jama.2020.2648 
14. Giusti B, Gori AM, Alessi M, Rogolino A, Lotti E, Poli D et al (2020) Sars-CoV-2 induced coagulopathy and prognosis in hospitalized patients: a snapshot from Italy. Thromb Haemost. https ://doi.org/10.1055/s-0040-1712918

15. Zhang L, Yan X, Fan Q, Liu H, Liu X, Liu Z, Zhang Z (2020) D-dimer levels on admission to predict in-hospital mortality in patients with Covid-19J. Thromb Haemost 18(6):1324-1329

16. Helms J, Tacquard C, Severa F, Leonard-Lorant I, Ohana M, Delabranche $\mathrm{X}$ et al (2020) High risk of thrombosis in patients in severe SARS-CoV-2 infection: a multicenter prospective cohort study. Intensive Care Med 46(6):1089-1098

17. Klok FA, Kruip MJHA, van der Meer NJM, Arbous MS, Gommers DAMPJ, Kant KM et al (2020) Incidence of thrombotic complications in critically ill ICU patients with COVID-19. Thromb Res 191:145-147

18. Cui S, Chen S, Li X, Liu S, Wang F (2020) Prevalence of venous thromboembolism in patients with severe novel coronavirus pneumonia. J Thromb Haemost 18(6):1421-1424

19. Marietta M, Ageno W, Artoni A, De Candia E, Gresele P, Marchetti M, Marcucci R, Tripodi A (2020) COVID-19 and haemostasis: a position paper from Italian Society on Thrombosis and Haemostasis (SISET). Blood Transfus 18:167-169

20. Tang N, Li D, Wang X, Sun Z (2020) Abnormal coagulation parameters are associated with poor prognosis in patients with novel coronavirus pneumonia. J Thromb Haemost JTH 18(4):844-847

21. Thachil J, Tang N, Gando S, Falanga A, Cattaneo M, Levi M, Clark C, Iba T (2020) ISTH interim guidance on recognition and management of coagulopathy in COVID-19. J Thromb Haemost 18(5):1023-1026

22. Manetta M, Coluccio V, Lippi M (2020) COVID-19, coagulopathy and venous thromboembolism: more questions than answers. Intern Emerg Med. https://doi.org/10.1007/s11739-020-02432-x

Publisher's Note Springer Nature remains neutral with regard to jurisdictional claims in published maps and institutional affiliations. 